\title{
EFFECTS OF TEXT MESSAGING ON ACADEMIC PERFORMANCE
}

\begin{abstract}
University students frequently send and receive cellular phone text messages during classroom instruction. Cognitive psychology research indicates that multi-tasking is frequently associated with performance cost. However, university students often have considerable experience with electronic multi-tasking and may believe that they can devote necessary attention to a classroom lecture while sending and receiving text messages. In the current study, university students who used text messaging were randomly assigned to one of two conditions: 1. a group that sent and received text messages during a lecture or, 2. a group that did not engage in text messaging during the lecture. Participants who engaged in text messaging demonstrated significantly poorer performance on a test covering lecture content compared with the group that did not send and receive text messages. Participants exhibiting higher levels of text messaging skill had significantly lower test scores than participants who were less proficient at text messaging. It is hypothesized that in terms of retention of lecture material, more frequent task shifting by those with greater text messaging proficiency contributed to poorer performance. Overall, the findings do not support the view, held by many university students, that this form of multitasking has little effect on the acquisition of lecture content. Results provide empirical support for teachers and professors who ban text messaging in the classroom.
\end{abstract}

Keywords: classroom technology; higher education; university student development

\section{INTRODUCTION}

Cellular telecommunications devices are a common classroom accessory among university students. A recent survey conducted at a U.S. university found that $95 \%$ of students reported bringing their cell phones to class on a daily basis (Tindell \& Bohlander, 2010). Additionally, $99 \%$ of students surveyed reported that they believed that they should be able to have their cell phones in class (Tindell \& Bohlander, 2010). Wireless communication increasingly occurs in the university classroom and may adversely impact learning (End, Worthman, Mathews, \& Wetterau, 2010). Up to $75 \%$ of students reported being distracted by a ringing cell phone during class. A recent empirical investigation found that students exposed to a ringing cell phone during a class presentation demonstrated poorer recall of content presented during the interruption (End et al., 2010).

Text messaging is an increasingly common form of communication; text messaging is convenient when the environment is too noisy for an auditory conversation, and it allows one to send off a quick question and receive a concise response without the normal conversational formalities. Surveys of U.S. adolescents indicate that $74 \%$ have used this modality compared with $44 \%$ of adults (Lenhart, Madden, \& Hitlin, 2005). A recent survey of students at a Midwestern university in the United States found that text messaging was the preferred communication method 
with 59\% preferring this mode of communication compared with $17 \%$ preferring phone calls; $9 \%$ instant messaging and $7 \%$ e-mail (Kim, 2009). Up to $90 \%$ of university students surveyed indicated that they have sent and/or received text messages during classroom presentations (Tindell \& Bohlander, 2010).

While cell phone ringing is distracting, students typically do not converse with the caller during lectures. In contrast, silent cellular phone text messaging permits extensive conversational exchanges during classes that may not be as obviously disruptive (Young, 2006). Anecdotal reports indicate that university students frequently send and receive text messages during their classes and that their instructors are often naïve about this practice. University students surveyed indicated that they can readily send and receive text messages without the instructor's awareness of their actions and those instructors would be "shocked" if they knew about the frequency of classroom texting (Tindell \& Bohlander, 2010). While students may believe that silent text messaging during class should be permitted if the practice occurs without disturbing other students, a significant proportion of those surveyed believe that texting creates a distraction to those sitting nearby (Tindell \& Bohlander, 2010). Classroom text messaging may also be a distraction to instructors. A recent controversy involved a professor who followed through on his threat to walk out of class if he observed a student engaged in text messaging during his lecture (Jaschik, 2008).

While not a focus of the current study, silent communication offered by text messaging raises concerns about examination security. About 10 percent of students surveyed reported sending or receiving text messages during exams. More disturbing is the finding that 3 percent of these university students indicated that, through text messaging, they had conveyed or received information directly relevant to the exam (Tindell \& Bohlander, 2010). Text messaging as a practice presents new challenges to insuring academic integrity.

Many University students believe that they have mastered the ability to attend to, retain, and respond to multiple sources and modalities of information simultaneously.

\section{THE AIM OF THE STUDY}

To examine whether multi-tasking, specifically sending and receiving text messages during an educational presentation, has an impact on retention of classroom material.

\section{MATERIALS AND METHODS}

A secondary aim was to determine if there were differences in retention of educational material related to text messaging proficiency. Cognitive psychology would suggest that participants who were more proficient at sending and receiving text messages may have more resources, such as attention and working memory, available for other cognitive demands such as attending to and retaining classroom lecture material.

Cognitive psychology suggests that texting while listening to a lecture may tax a finite attention pool (Ashcraft \& Klein, 2010). When compared with those performing a single task, participants alternating between distinct activities required additional transition time and demonstrated more errors (Vandierendonck, Christiaens, \& Liefooghe, 2008). The Unified Theory of the Multitasking Continuum model (Rosen, Lim, Carrier \& Cheever, 2011; Salvucci, Taatgen $\&$ Borst, 2009) suggests that there are four basic "modules" that are involved in most cognitive tasks. These include: “(a) a declarative memory module that handles factual knowledge, task instructions and episodic information; (b) a goal module which tracks progress; (c) a problem representation module which contains the information derived during learning that may be needed later in the process; and (d) a procedural module that connects all of the modules together and 
monitors the flow of information between modules" (Rosen et al., 2011, p.168).

In multitasking, the extent to which these tasks compete for cognitive resources will determine successful and efficient performance. In applying this view to the topic of the current study, these modules would be involved in both assimilating information from a classroom lecture and interactive communication through text messaging. When concurrent cognitive tasks require the same function(s), one task is delayed until the other one is completed (Rosen et al., 2011; Salvucci \& Taatgen, 2011). This competition should reduce optimal performance of one or both tasks.

However, attention and task performance may also be modality-specific involving distinct attention pools. Efficiency and accuracy could be determined by whether attention for both activities is drawn from the same pool (Anderson et al., 2005). Since much of classroom instruction relies on auditory modalities while texting taps visual processing skills, one could argue that paying attention to a college lecture and communicating via text messages can occur simultaneously since different attentional "pools" are involved. New or difficult tasks require more attention as compared with simple, more practiced, tasks. Similar to other types of keyboarding, text messaging proficiency is likely to be reflected in performance speed and accuracy.

In the current study, the impact of text messaging during an academic lecture was assessed by comparing performance on a test of lecture content by students engaged and not engaged in text messaging. If a multiple cognitive resource model is applicable to text messaging, participants with greater text messaging proficiency should perform better on the test of lecture content since for these students, text messaging should be relatively "automatic" and less demanding of cognitive resources.

\section{Participants}

A total of 37 (7 males, 30 females) students at a midwestern university were randomly assigned to each of the two conditions. The only requirements for participation were cellular telephone ownership and experience with text messaging.

\section{Materials and Procedures}

Participants used their own cell phones to ensure accuracy. A 160 characters or 30 "word" text messaging test was administered to document the participants' text messaging speed. For this task, they were instructed to employ any generally accepted abbreviations used in their normal texting, for example using " 2 " instead of "to", "two" or "too".

Both groups then watched and listened to a ten minute videotaped lecture about building the Mackinac Bridge, a large suspension bridge in northern Michigan. During the presentation, one group, through their cellular phone, received and answered 15 standardized questions sent by one of the investigators. The other group observed and heard the presentation without engaging in text messaging. These text message conversations were in the informal format customarily used by experienced text message users. After the film presentation, both groups completed a 21 question quiz, 16 of the questions corresponded to the lecture while the other questions focused on the participants' cell phone model and opinions about the use of personal electronics in the classroom.

\section{RESULTS}

The results of a one-way analysis of variance (ANOVA) indicated a significant difference $(\mathrm{F}=10.71, \mathrm{p}<.002)$ between groups on the post-lecture test with the lecture only condition (M $=10.63, \mathrm{SD}=2.87)$ performing significantly better than the lecture and text messaging group $(\mathrm{M}$ $=7.44, \mathrm{SD}=3.05)$. These findings provide support for the view that engaging in text messaging 
does adversely impact retention of classroom material.

Using a median split, in which participants' scores for speed of text messaging were the basis for classification of participants into two groups (fast and slow), quiz scores were compared with a one-way analysis of variance (ANOVA) for fast and slow text messaging groups. Postlecture quiz scores were significantly higher for the slow $(\mathrm{M}=10.17, \mathrm{SD}=3.13)$ than for the fast $(\mathrm{M}=8.05, \mathrm{SD}=3.27)$ text messaging group $(\mathrm{F}=7.42, \mathrm{p}<.01)$. Counter-intuitively, this pattern suggests that participants who were less proficient at sending and receiving text messages had better retention of the classroom presentation.

\section{Discussion}

This study's findings suggest that text messaging during a lecture adversely impacts academic performance. Students engaging in text messaging during a class presentation demonstrated poorer performance on a test of lecture content administered immediately after the presentation. In a recent evaluation of text messaging as a form of class participation (e. g., asking questions of the presenter during the course of a lecture), students indicated that keying in the messages was a significant distraction causing them to miss important class content (Markett, Sanchez, Weber \& Tangney, 2006). While the silent nature of texting likely distracts fewer students than a ringing cell phone (End et al., 2010), 30\% of survey respondents described students who engaged in text messaging as diverting their attention (Markett et al., 2006).

The current findings are consistent with a view that engaging in text messaging during a classroom lecture involves competition for the same cognitive resources. From this perspective, there is likely to be a temporary decrement in performance while the student is switching from attending to the lecture to text messaging or vice versa.

We also found that those who text message at a slower speed scored significantly higher on the test of lecture content than those who were faster. Several possible explanations can be offered for this pattern of results. First, Sdoia and Ferlazzo (2008) demonstrated that switching to a less recently executed task has less of a performance cost than changing to one recently executed. This finding is consistent with the results of the current study in that when compared with less skilled texters, participants with greater texting proficiency demonstrated less mastery of the lecture content. A possible second factor is that while practice often reduces switch cost when multi-tasking, executing a recently practiced task may actually increase performance cost (Yeung, Monsell, 2003). Together with the current results, these previous findings suggest among the current participants, those who text message frequently actually spend more time shifting cognitive sets resulting in poorer retention of lecture material.

Besides text messaging proficiency, there has been at least one other recent study examining possible factors impacting the text-messaging-academic performance relationship. A recent study of business students found that the performance costs associated with texting did not differ by gender (Ellis, Daniels, \& Jauregui, 2010). While one might hypothesize that university students with higher average marks would have better developed cognitive skills for multitasking, the performance costs of texting do not appear to be influenced by cumulative academic performance. Ellis, Daniels, and Jauregui (2010) found that the adverse impact of texting during a classroom presentation was no different among students with higher versus lower grade point averages.

University students raised in an era of ever-expanding electronic communication, often believe in their ability to simultaneously attend to multiple linguistic inputs of different modalities. While warranting further research, the current study's results provide some empirical support for 
faculty bans on text messaging during class. The second author has referred to the results of this study in establishing classroom "ground rules" at the beginning of the semester. Students should be made aware that text messaging during lectures may result in poorer examination performance.

\section{CONCLUSIONS}

In the current study, university students reporting experience with sending and receiving text messages were randomly assigned to one of two conditions: a lecture during which participants received and responded to a series of text messages or the same lecture but without the text messaging activity who engaged in text messaging during a classroom presentation.

Those students engaging in text messaging during the presentation demonstrated poorer performance on a test of the content of a 30-minute class presentation immediately afterwards.

Of interest, students judged to be more proficient at sending and receiving text messages as evidenced by their faster text messaging speed, demonstrated poorer recall of the classroom lesson's content.

The current results suggest that in the university classroom, multi-tasking occurs at the cost of retention and/or retrieval of information. From the perspective of the Unified Theory of Multitasking Continuum, it is likely that the goal directed semantic processes involved in responding to a text message interfere with adequately attending to lecture content and rehearsing it adequately to encode in memory

Hopefully, our findings will stimulate further research in this area. In the meantime, banning the use of personal communication devices during classroom presentations appears to be a reasonable practice-benefiting both the "texter" as well as their fellow students. "No-text messaging" policies are increasingly common on syllabi in universities in the United States. University orientation programs are increasingly including presentations for incoming students on technology etiquette in the classroom (Bugeja, 2007). When taken together with basic neurocognitive research, the results of the current study suggest a connection between "good manners" in the classroom and academic success.

\section{REFERENCES}

Anderson, G. S., Courtney, A., Plecas, D. \& Chamberlain, C. (2005). Multi-tasking behaviors of general duty police officers. Police Practice and Research, 6, 39-48.

Ashcraft, M. H., Klein, R. (2010). Cognition. Toronto: Pearson Canada.

Bugeja, M. J. (2007, January 27). Distractions in the wireless classroom - advice. The Chronicle of Higher Education. Retrieved January 13, 2012, from http://chronicle.com/.

Ellis, Y., Daniels, B. W. \& Jauregui, A. (2010). The effect of multitasking on the grade performance of business students. Research in Higher Education Journal, 8, 1-10. Retrieved January 10, 2012, from http:// aabri.com/manuscripts/.

End, C. M., Worthman, S., Mathews, M. B., \& Wetterau, K. (2010). Costly cell phones: The impact of cell phone rings on academic performance. Teaching of Psychology, 37, 55-57.

Jaschik, S. (2008, April 2). If you text in class, this prof will leave. Inside Higher Education. Retrieved January 12, 2012, from http://www.insidehighered.com/.

Kim, G. (2009, March 24). Text overtakes IM, email, voice among college mobile users, J. Kostek (Ed.). Retrieved January 13, 2012, from http://technews.tmcnet.com/. 
Lenhart, A., Madden, M. \& Hitlin, P. (2005). Teens and technology: youth are leading the transition to a fully wired and mobile nation. Washington, D. C.: Pew Internet \& American Life Project.

Markett, C., Arndeillo Sanchez, I., Weber, S., \& Tangney, B. (2006). Using short message service to encourage interactivity in the classroom. Computers \& Education, 46, 280-293.

Rosen, L. D., Lim, A. F., Carrier, M. \& Cheever, N. A. (2011). An empirical examination of the educational impact of text-message induced task switching in the classroom: Educational implications and strategies to enhance learning. Psicologia Educativa, 17, 163-177.

Salvucci, D. D. \& Taatgen, N. A. (2011). The multitasking mind. New York: Oxford University Press.

Salvucci, D. D., Taatgen, N. A. \& Borst, J. P. (2009). Toward a unified theory of the multitasking continuum: From concurrent performance to task switching, interruption and resumption. Proceedings of the SIGCHI Conference on Human Factors in Computing Systems: CHI 2009. New York: ACM Press, pp.1819-1828.

Sdoia, S., Ferlazzo, F. (2008). Stimulus-related inhibition of task set during task switching. Experimental Psychology, 55, 322-327.

Tindell, D. R., Bohlander, R. W. (2010). The use and abuse of cell phones and text messaging in the classroom: A survey of college students. Wilkes University News Archives. Retrieved January 11, 2012, from http://www.wilkes.edu/.

Vandierendonck, A., Christiaens, E. \& Liefooghe, B. (2008). On the representation of task information in task switching: Evidence from task and dimension switching. Memory \& Cognition, 36, 1248-1261.

Yeung, N., Monsell, S. (2003). The effects of recent practice on task switching. Experimental Psychology, 29, 919-936.

Young, J. R. (2006). Students passing notes in class via text message. The Chronicle of Higher Education. Retrieved January 13, 2012, from http://chronicle.com/.

Ph.D., MPH H. Russell Searight

Associate Professor of Psychology

Lake Superior State University

Address: 650 W. Easterday Ave, Sault Sainte Marie, MI 49783

Phone: 906-632-3586

E-mail: hsearight@1ssu.edu

B.S. Amanda Barks

Department of Psychology

Lake Superior State University

Ph.D. Susan H. Ratwik

Professor of Psychology

Lake Superior State University 